\title{
Maintenance of the corneal epithelium is carried out by germinative cells of its basal stratum and not by presumed stem cells of the limbus
}

\author{
A. Haddad ${ }^{1}$ and S.J. Faria-e-Sousa $^{2}$ \\ ${ }^{1}$ Departamento de Biologia Celular e Molecular, Faculdade de Medicina de Ribeirão Preto, Universidade de São Paulo, \\ Ribeirão Preto, SP, Brasil \\ ${ }^{2}$ Departamento de Oftalmologia, Faculdade de Medicina de Ribeirão Preto, Universidade de São Paulo, Ribeirão Preto, SP, Brasil
}

\begin{abstract}
The purpose of this investigation was to analyze the proliferative behavior of rabbit corneal epithelium and establish if any particular region was preferentially involved in epithelial maintenance. $\left[{ }^{3} \mathrm{H}\right.$ ]-thymidine was injected intravitreally into both normal eyes and eyes with partially scraped corneal epithelium. Semithin sections of the anterior segment were evaluated by quantitative autoradiography. Segments with active replication (on) and those with no cell division (off) were intermingled in all regions of the tissue, suggesting that the renewal of the epithelial surface of the cornea followed an on/off alternating pattern. In the limbus, heavy labeling of the outermost layers was observed, coupled with a few or no labeled nuclei in the basal stratum. This suggests that this region is a site of rapid cell differentiation and does not contain many slow-cycling cells. The conspicuous and protracted labeling of the basal layer of the corneal epithelium suggests that its cells undergo repeated cycles of replication before being sent to the suprabasal strata. This replication model is prone to generate label-retaining cells. Thus, if these are adult stem cells, one must conclude that they reside in the corneal basal layer and not the limbal basal layer. One may also infer that the basal cells of the cornea and not of the limbus are the ones with the main burden of renewing the corneal epithelium. No particular role in this process could be assigned to the cells of the basal layer of the limbal epithelium.
\end{abstract}

Key words: Cornea; Epithelium; Autoradiography; Germinative cells; Stem cells; Limbus

\section{Introduction}

The integrity of the squamous, nonkeratinized stratified corneal epithelium is essential for adequate light refraction and to achieve good vision. This epithelium is the foremost surface of the eye, and, of course, is the most vulnerable to different types of external injuries leading to cell loss. Nature has endowed all epithelia with the property of self-renewal. This occurs either under physiological conditions $(1,2)$ or following an abnormal epithelial loss (3). The renewal of the corneal epithelium has been studied using different techniques such as the arrest by colchicine (4), 5-bromo-2-deoxyuridine (BrdU) in association with immunohistochemistry $(5,6)$, and $\left[{ }^{3} \mathrm{H}\right]-$ thymidine $\left(\left[{ }^{3} \mathrm{H}\right]-\mathrm{TdR}\right)$ administration together with autoradiography $(7,8)$. These studies have demonstrated that renewal of the corneal epithelium follows an established pattern for all types of stratified epithelia, in which cells originate in the deepest (basal) layer and are sloughed off at the most superficial stratum $(6,8,9)$. The time required for this turnover varies among animal species $(10,11)$.

The corneal epithelium is characterized by keratin types 3 and 12, which are found in the intermediate filaments of its cells (12). Since this is the only phenotype expressed by this epithelium, none of its basal cells can be considered to be stem cells. Real adult epithelial stem cells, which generate different cell types (2), are found, for example, at the bottom of the crypts of the small intestine mucosa. The basal cells of the corneal epithelium are, in fact, germinative cells.

The idea that adult stem cells could be part of the corneal epithelium originated from the finding of Schermer et al. (12) that the basal cells of the transitional region between the cornea and the conjunctiva, known as the

Correspondence: S.J. Faria-e-Sousa, Departamento de Oftalmologia, Faculdade de Medicina de Ribeirão Preto, USP, Av. Bandeirantes, 3900, 14049-900 Ribeirão Preto, SP, Brasil. Fax: +55-16-3623-2956. E-mail: sidneyjfs@gmail.com 
limbus, do not react to anti-keratin 3 and 12 antibodies. This would indicate that the cells are immature and are therefore stem cells. This assumption has to be made with caution because this is a necessary condition, but by itself not sufficient to characterize stem cells. Moreover, the lack of reactivity to these keratins may be an artifact of tissue fixation related to the antibody concentration and to the degree of stimulus to cell regeneration (13). It may also depend on the definition of the anatomical limits of the limbus in different species as well as differences in its epithelial cell composition in the several quadrants of the eye (14). In spite of the limitations of Schermer's report (12), a wave of investigations trying to find a bona fide marker for the purported corneal stem cells have been conducted since then (15-23). However, when more critical and more consistent studies were performed, the existence of a reliable marker for adult limbal corneal stem cells has been called into question. Every proposed marker has been shown to be not unique soon after its publication. Thus, the ABCG2 transporter (16), considered the best marker for corneal limbal clonogenic cells (18), is in fact expressed by small Langerhans cells in the basal epithelium of the limbus, and which were mistakenly assumed to be stem cells (22). Another purported marker, p63 $(17,24)$, was promptly excluded because it is ubiquitously expressed in all cells in mitosis (25). It is also expressed in corneal epithelial cells surrounding small wound sites in the center of the cornea created 1 day earlier (26). Another antibody, known as 4G10.3 (antialpha enolase), was proposed as a bona fide marker after it was verified that it reacts with limbal cells in corneas in which the central epithelium was scraped (15). In experiments carried out in our laboratory, this antibody was strongly reactive with the epithelial cells at the center of the cornea if the limbus plus the peripheral corneal epithelium were removed (27). It also reacted with all layers of the retina. In summary, most investigators no longer accept the idea that a reliable marker for purported limbal stem cells will be found.

Another line of research attempted to characterize limbal stem cells using autoradiography after $\left[{ }^{3} \mathrm{H}\right]-\mathrm{TdR}$ administration (28-30). According to these studies the basal cells of the limbal epithelium would be slow-cycling and label-retaining, meaning that after the administration of the DNA precursor, very few cells would take up the label; but, once labeled in a previous cycle, they would remain as such for at least 4 weeks. Those cells would behave as stem cells, and their centripetal migration would be essential for corneal epithelium maintenance by supplying the basal stratum with fresh "transient amplifying cells" to replace "old" or "lost" cells. This proposal overlooks the proliferative potential of the basal cells more centrally located in the cornea, and implies that the socalled $X, Y, Z$ hypothesis is valid for explaining the mode of epithelial renewal (31). It was conceived at a time when there was very little experimental evidence to support it. It presumes that centripetal migration is a necessary condition for the proper renewal. Current investigations conducted in different laboratories indicate the opposite. Thus, based on autoradiographic findings, Beebe and Masters (6) and Haskjold et al. (7) did not detect such events. Destroying the limbus by cauterization, Majo et al. (32) verified corneal epithelium maintenance for more than 4 months. Repeated removal of the limbal epithelium during a 4-month interval did not disturb the proliferative capability of the centrally located corneal epithelium (3).

Experimental data on the speed of cell migration from the limbus toward the center of the cornea are scarce. It was found in mice that migration could proceed at 17 (33) or $26 \mu \mathrm{m} /$ day (34). The chordal radius of the rabbit cornea is $7 \mathrm{~mm}$. If this same rate of migration is considered for rabbits, it would take between 270 and 411 days for a limbal cell to reach the center of the cornea. It has been demonstrated that a daughter cell reaches the outermost layer of the corneal epithelium in about 15 days, moving a distance of $40 \mu \mathrm{m}$ (8). The epithelium would be lost if it took as long as 1 year for the arrival of replacement cells coming from the limbus. Evidence for the high proliferative potential of centrally located basal cells has been found by a procedure, eliminating a small epithelial area in the center of the cornea. The cells surrounding the gap were sufficient to repair the wound with no need for mobilization of limbal cells $(26,35)$.

When comparing our previous results with those of other investigators (28-30), one finds important differences in the autoradiographic processing of the specimens that could explain conflicting conclusions. Other investigators performed autoradiography using paraffin or frozen sections, in which case, the liquid photographic emulsion penetrates into the sections, causing artifacts and resulting in poor resolution (36). In our experiments, semithin resin sections of tissue samples were processed by the same techniques used in transmission electron microscopy. This provided the best tissue preservation, the highest resolution, and a minimum of artifacts (37). In this technique, the resolution of the location of the silver grains in relation to the source of radiation is equal to that of the light microscope, allowing the identification and discrimination of cell components that are very close to each other.

Apparently, most of the investigations carried out in the last 20 years have focused on proving the existence of adult stem cells in the limbal epithelium. The role of the germinative basal layer in the renewal process of the corneal epithelium has been overlooked. The purpose of this investigation is to study the proliferative behavior of the whole epithelial layer of the cornea by means of autoradiography after intravitreal injection of $\left[{ }^{3} \mathrm{H}\right]-\mathrm{TdR}$. This method has been used for more than 50 years in investigating cell proliferation (38). Although more timeconsuming than other methods, such as the BrdU technique, it is the only reliable way to monitor the fate 
of labeled cells for months after the administration of the DNA precursor (36).

\section{Material and Methods}

The animals used in the experiments were male albino rabbits (Oryctolagus cuniculus) weighing 2.5-2.8 kg. They were anesthetized with a mixture of ketamine hydrochloride (50 mg/kg; Parke Davis, USA) and $4 \mathrm{mg} / \mathrm{kg}$ xylazine hydrochloride (Schering Plough Coopers, Brazil), injected intramuscularly. Before the intravitreal injection, topical anesthesia was administered by dropping proparacaine hydrochloride (Anestalcon ${ }^{\circledR}$, Alcon, Brazil) on the ocular surface. $\left[{ }^{3} \mathrm{H}\right]-\mathrm{TdR}$, specific activity $25 \mathrm{Ci} / \mathrm{mmol}$ or $925 \mathrm{GBq} / \mathrm{mmol}$ (Amersham, UK), was evaporated to complete dryness and redissolved in saline at a concentration of $20 \mu \mathrm{Ci} / 50 \mu \mathrm{L}(20 \times 37 \mathrm{kBq} / 50 \mu \mathrm{L})$. All animals were handled according to the Animals in Ophthalmic and Vision Research (ARVO) statement.

Six rabbits were intravitreally injected with $50 \mu \mathrm{L}$ of this DNA precursor, and killed $8 \mathrm{~h}$ afterwards by an intravenous injection of sodium thiopental. After enucleation, the eyes were fixed for 1 day by immersion in $4 \%$ formaldehyde in $0.1 \mathrm{M}$ Sorensen's phosphate buffer. The corneas were isolated from the globe by a frontal 2-3-mm section behind the cornea-sclera junction, divided into two halves and embedded in paraffin. Six of these halves, chosen at random, were used to obtain $5-\mu \mathrm{m}$ thick sections that were stained by the periodic acid-Schiff reagent (PAS) technique before being processed for autoradiography. The study of the distribution of labeled nuclei from the limbus to the corneal center was performed using a micrometer disk (Zeiss \#474004, Germany) inserted into the eyepiece of a binocular microscope. At a $400 \times$ magnification, the side of the main square of the micrometer disk measures $0.25 \mathrm{~mm}$ or $250 \mu \mathrm{m}$. One side of the square was placed over the conjunctiva-limbus junction. The specimens were then moved at $0.25-\mathrm{mm}$ steps until the completion of 28 measurements toward the center of the cornea, covering an extension of $7 \mathrm{~mm}$, which is the chordal radius of the rabbit cornea. The results are reported as the number of segments with and without labeled nuclei per millimeter of corneal section.

In another series of experiments, 8 rabbits were killed in groups of two at $6 \mathrm{~h}, 2,28$, and 90 days after a single intravitreal injection of the isotope. After fixation, the corneas with the adjacent conjunctiva were chopped to get small pieces from all regions of each quadrant of the cornea, followed by the processing of these fragments for routine technique of transmission electron microscopy (8). Iron-hematoxylin prestained semithin sections were processed for autoradiography and analyzed to locate labeled nuclei inside the corneal epithelium as well as to estimate the labeling index (number of labeled nuclei per 100 cells).
Four rabbits were intravitreally injected three times at intervals of 4 days and killed in groups of two at 12 and 49 days after the first injection. After autoradiographic processing, the labeling index was estimated not only for the whole epithelium but also for the respective epithelial layers of the cornea and limbus.

Autoradiography was performed using type LM1 liquid photographic emulsion (Amersham), developed in D-170 (Kodak formula) and fixed in $24 \%$ sodium thiosulfate. The details of this technique have been fully described elsewhere (8).

In another experiment, aimed at analyzing morphologically the regeneration of the corneal epithelium, the right eyes only were marked at the center of the cornea with trephine blades of 3.5 or $6 \mathrm{~mm}$ in diameter, and all the epithelium outside of this area was scraped with an ophthalmic spatula until reaching the conjunctiva to ensure elimination of the limbus. Four were killed in groups of two as early as $36 \mathrm{~h}$ and as late as 3 months after scraping. The paraffin sections of these corneas were stained with PAS plus hematoxylin and also for the immunohistochemical technique to identify epithelial keratins using the antibody AE5 (14). Autoradiography was also employed in the analysis of this series of experiments in rabbits that were injected soon after the debridement.

The statistical tests (Student $t$ and Pearson $r$ ) were carried out with the software JMP (SAS Inc., USA). The results were considered to be significant at $\mathrm{P}<0.05$.

\section{Results}

Figure 1 shows the distribution of labeled nuclei in paraffin sections of the corneal epithelium of 6 animals killed $8 \mathrm{~h}$ after the intravitreal injection of $\left[{ }^{3} \mathrm{H}\right]-\mathrm{TdR}$. The measurements started at the limbus $(\mathrm{L})$ and ended at the corneal center. The boxes in the figure represent $250-\mu \mathrm{m}$ long segments and the numbers of labeled nuclei are indicated. Most of the labeled nuclei were in the basal and the immediate suprabasal layers. In each section, there were areas where a small number of cells were dividing (gray boxes) intermingled with segments with no mitosis (white boxes) indicated by the presence or absence of nuclear labeling, respectively. The pattern was similar in the 6 corneas. The differences among them were in the distribution of the labeled nuclei inside the segments. There was a moderate (Pearson $r=0.532$ ) albeit statistically significant $(P=0.0035)$ correlation between the number of labeled nuclei found in each segment and its distance from the limbus, indicating that the greater the distance from the limbus, the higher the probability of observing labeled nuclei.

The autoradiographs of semithin sections revealed labeled nuclei in both the basal and the first suprabasal layers of the limbal epithelium in rabbits killed $6 \mathrm{~h}$ after a single injection of the DNA precursor (Figure 2). This was 


\begin{tabular}{|c|c|c|c|c|c|c|c|c|c|c|c|c|c|c|c|c|c|c|c|c|c|c|c|c|c|c|c|c|}
\hline 0 & 1 & 1 & 2 & 1 & 0 & 0 & 1 & 3 & 2 & 0 & 1 & 1 & 3 & 1 & 0 & 2 & 1 & 0 & 2 & 0 & 1 & 2 & 0 & 2 & 0 & 2 & 3 & Rabbit 6 \\
\hline & & & & & & & & & & & & & & & & & & & & & & & & & & & & \\
\hline 0 & 0 & 0 & 1 & 1 & 2 & 0 & 0 & 2 & 1 & 0 & 1 & 0 & 0 & 1 & 0 & 0 & 0 & 2 & 0 & 1 & 2 & 1 & 0 & 2 & 3 & 1 & 0 & Rabbit 5 \\
\hline & & & & & & & & & & & & & & & & & & & & & & & & & & & & \\
\hline 1 & 0 & 0 & 0 & 1 & 0 & 1 & 2 & 1 & 0 & 1 & 2 & 1 & 1 & 0 & 0 & 1 & 1 & 1 & 1 & 1 & 3 & 2 & 4 & 2 & 1 & 2 & 3 & Rabbit 4 \\
\hline & & & & & & & & & & & & & & & & & & & & & & & & & & & & \\
\hline 2 & 0 & 3 & 1 & 1 & 4 & 1 & 0 & 0 & 1 & 1 & 0 & 2 & 0 & 0 & 2 & 4 & 1 & 1 & 2 & & 2 & 0 & 3 & 0 & 3 & 0 & 1 & Rabbit 3 \\
\hline & & & & & & & & & & & & & & & & & & & & & & & & & & & & \\
\hline 0 & 0 & 2 & 1 & 4 & 0 & 0 & 0 & 1 & 0 & 0 & 1 & 0 & 1 & 1 & 0 & 1 & 0 & 0 & 3 & 0 & 1 & 2 & 0 & 1 & 2 & 6 & 4 & Rabbit 2 \\
\hline & & & & & & & & & & & & & & & & & & & & & & & & & & & & \\
\hline 3 & 1 & 1 & 0 & 2 & 0 & 1 & 0 & 1 & 1 & 0 & 3 & 1 & 1 & 1 & 0 & 0 & 0 & 2 & 0 & 1 & 0 & 2 & 4 & 1 & 1 & 0 & 5 & Rabbit 1 \\
\hline
\end{tabular}

Figure 1. Diagram showing the crude distribution of the labeled nuclei in paraffin sections of the corneal epithelium of 6 animals killed $8 \mathrm{~h}$ after the intravitreal injection of $\left[{ }^{3} \mathrm{H}\right]-\mathrm{TdR}$. The measurements started at the limbus $(\mathrm{L})$ and finished at the corneal center. The boxes represent $250-\mu \mathrm{m}$ long segments and the numbers inside them the labeled nuclei; white boxes are segments with no labeling. The farther from limbus the higher the probability of observing labeled nuclei $(P=0.0035$; Pearson $r=0.532)$.

quite clear in regions of extraocular muscle insertions where the boundary between the clear basal cells and the suprabasal cells is sharp (Figure 2B). At this early interval,

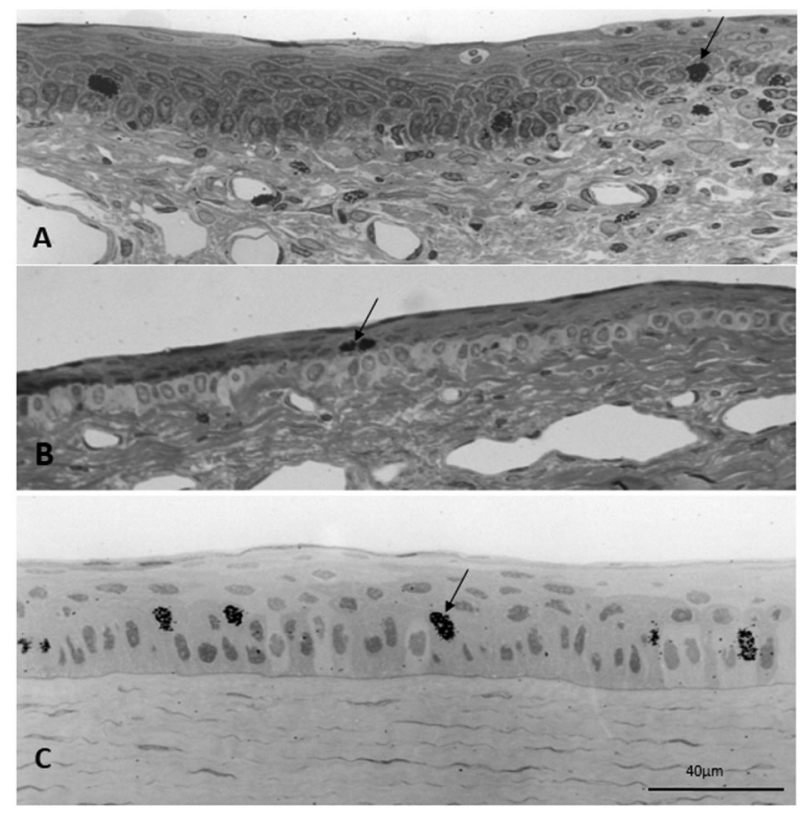

Figure 2. Autoradiography of semithin sections of control eyes injected with $\left[{ }^{3} \mathrm{H}\right]-\mathrm{TdR}$. Six hours after the intravitreal injection showing the limbus in a region in-between extraocular muscle insertions $(A)$ and at the insertion of the superior rectus muscle $(B)$. The central cornea is shown in Panel $C$. Labeled nuclei (arrows) were observed in the basal stratum and the immediate superior layer, either in the limbus and central cornea. the labeling index for the whole epithelium was 0.61 , and more than $93 \%$ of the labeled cells were found in the basal stratum. The overall labeling index at 2 days after injection increased sharply to $7.3 \%$; and more than $50 \%$ of labeled corneal epithelial cells were basal cells. The labeling index increased to $8.2 \%$ at 28 days, and about $26 \%$ of the labeled nuclei were found in the basal stratum. At 90 days, very few lightly labeled nuclei were observed in the corneal epithelium.

The results of the experiments conducted in the 4 rabbits injected three times with $\left[{ }^{3} \mathrm{H}\right]-\mathrm{TdR}$ intravitreally are shown in Table 1 and Figure 3 . The labeling indices of the basal layer of the cornea were significantly larger than the corresponding indices of the limbus. The labeling indices of the suprabasal layers of the cornea and the limbus did not differ significantly at either of the time intervals. The ratio between the labeling index of the basal and suprabasal strata remained virtually unchanged at 12 and 49 days after injection (Table 1).

In some sections, all the labeled nuclei were in the outermost layer and none in the remaining layers (Figure $4 \mathrm{~A})$. In others, the outermost layer was heavily labeled, the intermediary layers were lightly labeled, and the basal stratum was unlabeled (Figure 4B). In these cases, the newly formed cells from the basal stratum probably started migrating immediately after mitosis. In still other segments, all layers were labeled alike, but the labeling of the basal layer tended to last longer (Figure 4D). In this case, the daughter cells most likely undergo several divisions before migrating outwardly.

At $36 \mathrm{~h}$ after corneal epithelial scraping, which left an intact central circular area of $6 \mathrm{~mm}$, most of the corneal surface was covered by an epithelium made up predominantly 
Table 1. Labeling indices for the epithelium covering the limbus and the cornea of non-stimulated rabbits injected 3 times with $\left[{ }^{3} \mathrm{H}\right]-\mathrm{TdR}$, at intervals of 4 days, and killed at 12 and 49 days after the first injection.

\begin{tabular}{lrrrrr}
\hline Cells & \multicolumn{3}{c}{ Limbus } & & \multicolumn{2}{c}{ Cornea } \\
\cline { 2 - 3 } \cline { 5 - 6 } & 12 days & 49 days & & 12 days & 49 days \\
\hline Basal & $2.9 \pm 1.2$ & $3.8 \pm 1.7$ & & $14.7 \pm 5.9$ & $17.8 \pm 6.5$ \\
Suprabasal & $12.3 \pm 4.1$ & $23.4 \pm 9.3$ & & $24.9 \pm 8.0$ & $23.0 \pm 7.0$ \\
\hline
\end{tabular}

Data are reported as means \pm SD of 4 fields of measurement of 100 cells each. The labeling indices of the cornea at 12 and 49 days were significantly higher than those of the limbus $\left(P_{12}=0.0078 ; P_{49}=0.0059\right.$, Student $t$-test $)$.

of squamous and low cuboidal cells. This newly formed epithelium was AE5-positive and reached the very periphery where a gap could be detected between the corneal epithelium and the unreactive conjunctival epithelium (Figure 5A-C). After 3 months, the regenerated epithelium had morphological and immunological features similar to the control eyes (Figure 5E), even in cases where the central circular area of intact epithelium was only $3.5 \mathrm{~mm}$. Autoradiographs demonstrated that the corneal epithelium was massively labeled with the DNA precursor (Figure 6).

\section{Discussion}

Intravitreal injection of $\left[{ }^{3} \mathrm{H}\right]-\mathrm{TdR}$ delivers this DNA precursor to the anterior chamber for nearly 2 days (8). In spite of this, the overwhelming majority of epithelial cells were not labeled by $8 \mathrm{~h}$ after the injection. The few labeled nuclei showed conspicuous heterogeneity. In the six sections evaluated, they were distributed unevenly throughout the basal stratum, with many $250-\mu \mathrm{m}$ segments
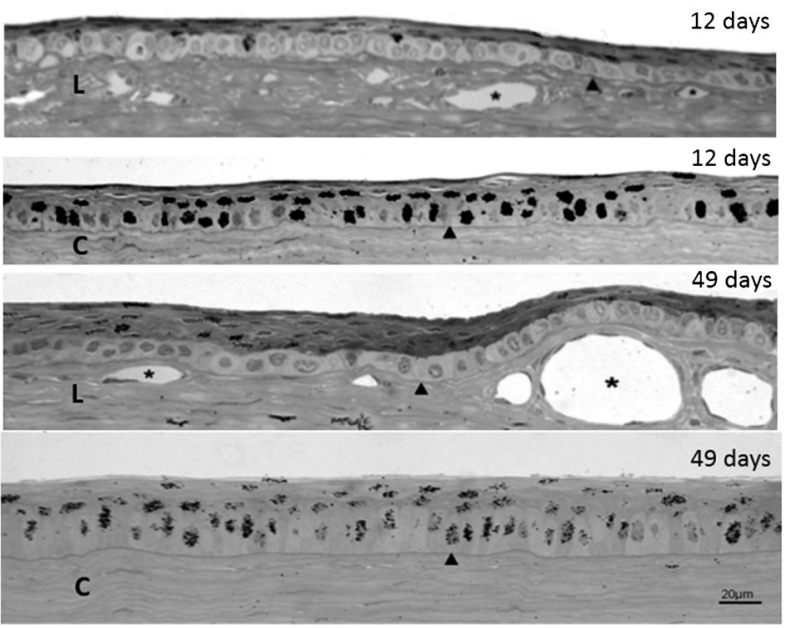

Figure 3. Autoradiography of semithin sections of rabbit eyes injected three times with $\left[{ }^{3} \mathrm{H}\right]-\mathrm{TdR}$ and killed at 12 and 49 days after the first injection, showing both the limbus $(L)$ and the center of the cornea $(\mathrm{C})$. The cuboid clear cells making up the basal stratum in the limbus are conspicuous. Arrowheads indicate the basal membranes; asterisks are in the lumen of blood vessels. showing no mitotic activity (Figure 1). Rationally, we cannot conclude that the few labeled cells in Figure 1 are the only ones responsible for the renewal of the corneal epithelium. It is more logical to assume that all the unlabeled cells of the basal stratum were in interphase in the 8-h period when the cornea was supplied by the radioactive precursor, albeit apt to divide at another time. The uneven distributions of labeled nuclei among different corneas are consistent with this interpretation. This finding

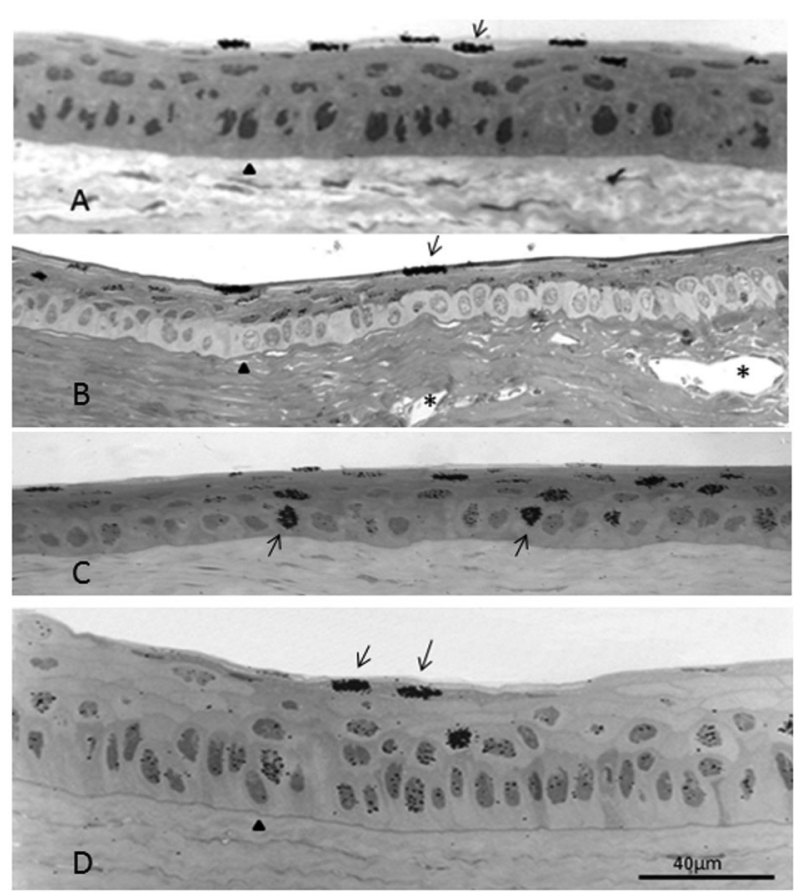

Figure 4. Autoradiography of sections of different regions of the same cornea 28 days after a single intravitreal injection of $\left[{ }^{3} \mathrm{H}\right]-$ $\operatorname{TdR}$. A, Heavily labeled nuclei in the outermost layer (arrow) and none in the other strata of the central cornea. B, Limbus at a muscle insertion; most of the labeled nuclei are in the suprabasal layers and none in the basal layer. $C$, Central region of the cornea exhibiting heavily labeled nuclei in the basal stratum. $D$, Lightly labeled nuclei in the basal and suprabasal strata and 2 heavily labeled nuclei in the outermost layer (arrows) of the central cornea. Arrowheads indicate the basal membranes; asterisks (in Panel $B$ ) are in the lumen of limbal vessels. 


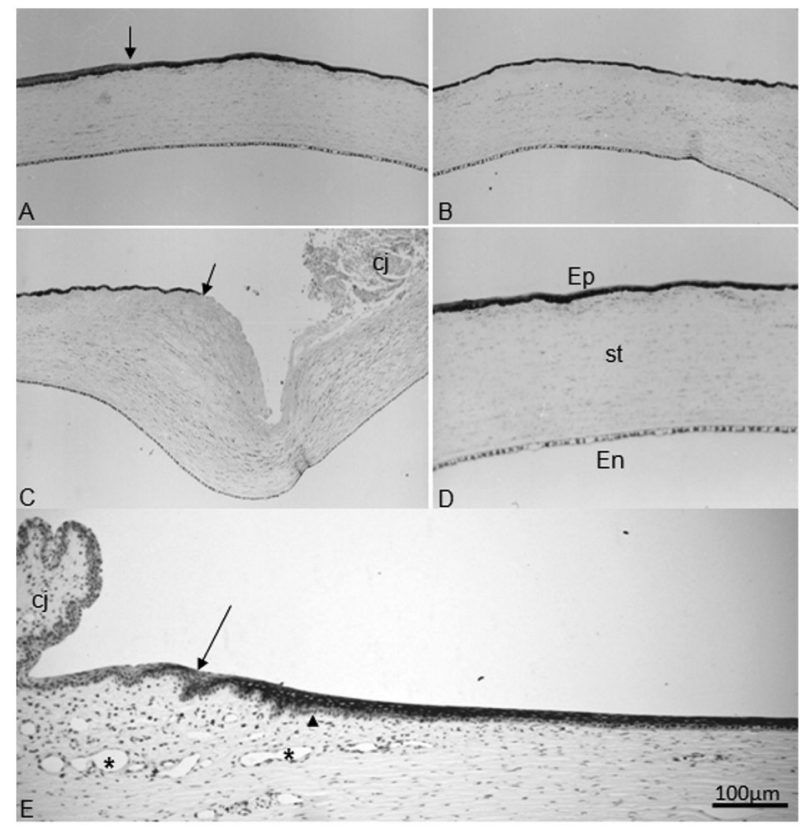

Figure 5. Low-power view of paraffin sections of a cornea immunostained with AE5 antibody without any counterstaining $36 \mathrm{~h}$ after scraping of the peripheral epithelium plus surgical excision of the limbus $(A-C)$. In these sequences of photomicrographs, a very strong reaction is observed in the corneal epithelium (Ep). A, Part of the original epithelium can be identified to the left of the vertical arrow. The rest of the epithelial covering is made up by newly regenerated cells. $B$, Continuation of plate $A$ toward the periphery. $C$, Epithelial covering ending at the valley caused by the resection of the limbal stroma (arrow). Part of the conjunctiva (cj) is seen on the right-hand side of the photomicrograph. $D$, The control cornea with all of its layers; Ep: epithelium; st: stroma; En: endothelium. $E$, The cornea 3 months after the surgical procedure stained with the AE5 antibody plus counterstaining with hematoxylin. The oblique arrow points to the limbus. The arrowhead identifies the basal membrane; asterisks are in the lumen of limbal vessels. Part of the conjunctiva (cj) is seen on the left-hand side of the plate.

suggests that the renewal of the epithelial surface of the cornea follows an on/off alternating pattern, with some cells replicating (on) and others in the interphase (off). Another interesting observation was that even at early intervals, it was already possible to find that the greater the distance from the limbus, the higher the probability of observing labeled nuclei. This finding suggests that the mitotic activity at the center of the cornea tended to be higher than in the corneal periphery and limbus.

When high-resolution autoradiographs of different regions of the cornea were compared, labeled nuclei were observed in all of them (Figure 2). It was mandatory, however, to carry out a broad sampling of areas in all quadrants because of the small numbers of mitosis occurring during short intervals such as $6 \mathrm{~h}$. At longer time intervals, the number of labeled nuclei increased and

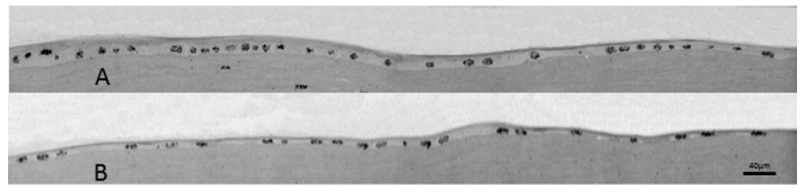

Figure 6. Autoradiography of semithin Epon sections prestained with iron-hematoxylin $36 \mathrm{~h}$ after the scraping of the peripheral epithelium plus excision of the corneoscleral zone 2 days prior to sacrifice. These photomicrographs were taken from a single section of the anterior region of the cornea. On the left-hand corner of plate $A$ is the border of the non-scraped epithelium. The right-hand corner of plate $B$ corresponds to the ending border of the newly formed epithelium. In $A$, on the region where the epithelium is stratified (far left), the $\left[{ }^{3} \mathrm{H}\right]-\mathrm{TdR}$-labeled nuclei are concentrated in the basal stratum. From this region toward the periphery, the epithelium is monolayered and practically all nuclei are labeled.

they were visualized throughout the epithelium without occupying all of its extension.

Migration of newly formed cells from the basal stratum may start immediately after mitosis, leaving segments with heavily labeled nuclei in the outermost layer and almost no labeling in the basal stratum (Figure 4A and B). Alternatively, the newly formed cells may undergo several mitotic cycles before starting their migration toward the surface. In this model, labeled cells in the basal layer coexist with labeled cells in the suprabasal strata (Figure $4 C$ and D). The multiple cycles of replication explain the detection of labeled cells in the basal layer, even at long intervals such as 28 days after a single injection of the DNA precursor. Some investigators found these cells only in the limbus, named them label-retaining cells, and speculated that they represented adult epithelial stem cells because of their slow-cycling mitotic pattern (28-30). Since these cells are also detected in the basal epithelium of the central cornea, either they are not adult stem cells or the corneal center also contains adult stem cells.

Concerning the limbus, even at $6 \mathrm{~h}$ after injection, labeled nuclei could be detected in the first suprabasal layer of the epithelium (Figure 2). At longer intervals, the suprabasal layers were the ones with most of the labeled nuclei (Figure 3, L-12 and L-49 days). If these cells have slow-cycling and label-retaining traits, then it is evidence against the existence of stem cells in the limbus.

The aim of the three injections was to increase and prolong the supply of $\left[{ }^{3} \mathrm{H}\right]-\mathrm{TdR}$ for the replicating cells. It is known that after an intravitreal injection of thymidine, the nucleotide remains available for incorporation into macromolecules in the eye tissues for 2-3 days (8). Therefore, it is possible to label numerous nuclei in cells that have undergone mitosis during a period of approximately 2 weeks. Furthermore, cells labeled during a cycle can give rise to others during the availability of the precursor, becoming heavily labeled. After cessation of the isotope supply, these heavily labeled nuclei can still be detected 
for a long period, even if they have gone through several rounds of divisions. This was the case for the corneas of rabbits killed at 49 days after the three intravitreal injections (Figure 3C, 49 days).

In assigning a labeled nucleus to one of the several layers of the corneal epithelium, it was considered that some basal cells had their nucleus in the immediate suprabasal stratum (39). This was even more precisely detected on the high-resolution autoradiographs used in this investigation. This technique also allowed for a sharper location of labeled nuclei in the limbal epithelium, particularly in regions of extraocular muscle insertions where the limit between the basal and the first suprabasal layer was more distinct. This would be extremely difficult to achieve in paraffin and frozen sections processed for autoradiography due to the small dimensions and the very close arrangement of epithelial cells in this particular region (14).

The fact that the ratio of the labeling indices of the basal and suprabasal layers, either from the cornea or from the limbus, remained virtually unchanged at 12 and 49 days after injection suggests that the relationship between the basal and suprabasal labeling indices is not random (Table 1). It must result from a perfect timing among cell proliferation in the basal stratum, vertical migration through the intermediate strata, and shedding in the outermost layer of the epithelium. The association of a nil (or small) labeling index of the basal layer, with higher labeling indices observed of the strata located above indicates that this region should have rapid cell differentiation. The faster the differentiation, the more rapid the migration to the suprabasal strata, and the lower the probability of nuclear labeling even by repeated exposure to $\left[{ }^{3} \mathrm{H}\right]-\mathrm{TdR}$. This is probably another argument against the presence of low cycling cells in the limbus.

The conspicuous and protracted labeling of the basal layer of the corneal epithelium suggests that the cells undergo repeated cycles of replication before moving into the suprabasal strata. This is the model of replication

\section{References}

1. Leblond CP, Greulich RC, Pereira JPM. Relationship of cell formation and cell migration in the renewal of stratified squamous epithelia. Adv Biol Skin 2014; 5: 39-57.

2. Cheng $\mathrm{H}$, Leblond $\mathrm{CP}$. Origin, differentiation and renewal of the four main epithelial cell types in the mouse small intestine. V. Unitarian theory of the origin of the four epithelial cell types. Am J Anat 1974; 141: 537-561, doi: 10.1002/aja.1001410407.

3. de Faria-e-Sousa SJ, Barbosa FL, Haddad A. Autoradiographic study on the regenerative capability of the epithelium lining the center of the cornea after multiple debridements of its peripheral region. Graefes Arch Clin Exp Ophthalmol 2010; 248: 1137-1144, doi: 10.1007/s00417010-1368-z.

4. Haskjold E, Refsum SB, Bjerknes R. Circadian variation in the mitotic rate of the rat corneal epithelium. Cell divisions compatible with the longest periods of nuclear retention of $\left[{ }^{3} \mathrm{H}\right]-\mathrm{TdR}$ and with the emergence of label-retaining cells. If the label-retaining cells are adult stem cells, as proposed elsewhere (28-30), one must conclude that the preferred site of these cells is the corneal and not the limbal basal epithelium. One may also infer that the basal cells of the cornea and not of the limbus are the ones really responsible for renewal of the corneal epithelium.

The objective of the experiment in which the epithelium was scraped, except for a small circular area in the center, was to test the regenerative pattern of the cornea without the presence of the limbus. It is well known that the first step in repairing a gap in the corneal epithelium is the sliding of the nearby epithelial cells over the stroma (40). As soon as the denuded area is covered by a single cell layer, a wave of mitoses ensues until complete healing of the wound is achieved. In rabbits, most of these events occur before the fourth day after scraping (35). In the present experiment, almost total epithelial regeneration was observed by $36 \mathrm{~h}$ and was fully completed in 3 months by an epithelium morphologically and immunologically similar to that of control corneas. No particular role could be assigned to the cells of the basal layer of the limbal epithelium.

These results, together with those of previous studies of our group $(3,8,14)$ and other investigators $(6,7,32)$, indicate that the renewal of the corneal epithelium can be carried out by its basal cells alone without any meaningful participation of the limbus. These results also suggest that, in the long run, the whole basal stratum is involved in the process, albeit not simultaneously.

\section{Acknowledgments}

Our gratitude is expressed to Vani M. Alves, Maria D.S. Ferreira, José A. Maulin, and Domingos S. Souza Filho for their technical assistance. Research supported by CNPq and FAEPA (Brazil). and migration are analyzed by a mathematical model. Virchows Arch B Cell Pathol Incl Mol Pathol 1989; 58: 123127, doi: 10.1007/BF02890063.

5. Szerenyi K, Wang X, Gabrielian K, LaBree L, McDonnell PJ. Immunochemistry with 5-bromo-2-deoxyuridine for visualization of mitotic cells in the corneal epithelium. Cornea 1994; 13: 487-492, doi: 10.1097/00003226-19941306000003.

6. Beebe DC, Masters BR. Cell lineage and the differentiation of corneal epithelial cells. Invest Ophthalmol Vis Sci 1996; 37: 1815-1825.

7. Haskjold E, Bjerknes R, Bjerknes E. Migration of cells in the rat corneal epithelium. Acta Ophthalmol 1989; 67: 91-96, doi: 10.1111/j.1755-3768.1989.tb00730.x.

8. Haddad A. Renewal of the rabbit corneal epithelium as investigated by autoradiography after intravitreal injection of 
${ }^{3} \mathrm{H}$-thymidine. Cornea 2000; 19: 378-383, doi: $10.1097 /$ 00003226-200005000-00024.

9. Marques-Pereira JP, Leblond CP. Mitosis and differentiation in the stratified squamous epithelium of the rat esophagus. Am J Anat 1965; 117: 73-87, doi: 10.1002/aja.1001170106.

10. Hanna C, O'Brien JE. Cell production and migration in the epithelial layer of the cornea. Arch Ophthalmol 1960; 64: 536-539, doi: 10.1001/archopht.1960.01840010538009.

11. Sharma A, Coles WH. Kinetics of corneal epithelial maintenance and graft loss. A population balance model. Invest Ophthalmol Vis Sci 1989; 30: 1962-1971.

12. Schermer A, Galvin S, Sun TT. Differentiation-related expression of a major $64 \mathrm{~K}$ corneal keratin in vivo and in culture suggests limbal location of corneal epithelial stem cells. J Cell Biol 1986; 103: 49-62, doi: 10.1083/jcb.103.1.49.

13. Faria-e-Sousa SJ, Haddad A. Restoration of the rabbit corneal surface after total epithelial debridement and complete limbal excision. Braz J Med Biol Res 2012; 45: 408-410, doi: 10.1590/S0100-879X2012007500023.

14. Goes RM, Barbosa FL, de Faria-e-Sousa SJ, Haddad A. Morphological and autoradiographic studies on the corneal and limbal epithelium of rabbits. Anat Rec 2008; 291: 191203, doi: 10.1002/ar.20635.

15. Zieske JD, Bukusoglu G, Yankauckas MA. Characterization of a potential marker of corneal epithelial stem cells. Invest Ophthalmol Vis Sci 1992; 33: 143-152.

16. de Paiva CS, Chen Z, Corrales RM, Pflugfelder SC, Li DQ. ABCG2 transporter identifies a population of clonogenic human limbal epithelial cells. Stem Cells 2005; 23: 63-73, doi: 10.1634/stemcells.2004-0093.

17. Di lorio E, Barbaro V, Ruzza A, Ponzin D, Pellegrini G, De Luca M. Isoforms of DeltaNp63 and the migration of ocular limbal cells in human corneal regeneration. Proc Natl Acad Sci U S A 2005; 102: 9523-9528, doi: 10.1073/pnas. 0503437102.

18. Schlotzer-Schrehardt U, Kruse FE. Identification and characterization of limbal stem cells. Exp Eye Res 2005; 81: 247-264, doi: 10.1016/j.exer.2005.02.016.

19. de Paiva CS, Pflugfelder SC, Li DQ. Cell size correlates with phenotype and proliferative capacity in human corneal epithelial cells. Stem Cells 2006; 24: 368-375, doi: 10.1634/stemcells.2005-0148.

20. Barbaro V, Testa A, Di lorio E, Mavilio F, Pellegrini G, De Luca M. C/EBPdelta regulates cell cycle and self-renewal of human limbal stem cells. J Cell Biol 2007; 177: 10371049, doi: 10.1083/jcb.200703003.

21. Blanpain C, Fuchs E. p63: revving up epithelial stem-cell potential. Nat Cell Biol 2007; 9: 731-733, doi: 10.1038/ ncb0707-731.

22. Chen W, Hara K, Tian Q, Zhao K, Yoshitomi T. Existence of small slow-cycling Langerhans cells in the limbal basal epithelium that express ABCG2. Exp Eye Res 2007; 84: 626-634, doi: 10.1016/j.exer.2006.11.006.

23. Lyngholm M, Vorum H, Nielsen K, Ostergaard M, Honore B, Ehlers $\mathrm{N}$. Differences in the protein expression in limbal versus central human corneal epithelium - a search for stem cell markers. Exp Eye Res 2008; 87: 96-105, doi: 10.1016/ j.exer.2008.05.001.

24. Pellegrini G, Dellambra E, Golisano O, Martinelli E, Fantozzi
I, Bondanza S, et al. p63 identifies keratinocyte stem cells. Proc Natl Acad Sci U S A 2001; 98: 3156-3161, doi: 10.1073/pnas.061032098.

25. Joseph A, Powell-Richards AO, Shanmuganathan VA, Dua HS. Epithelial cell characteristics of cultured human limbal explants. Br J Ophthalmol 2004; 88: 393-398, doi: 10.1136/ bjo.2003.018481.

26. Chahud F, Ramalho LN, Ramalho FS, Haddad A, RoqueBarreira MC. The lectin $\mathrm{KM}^{+}$induces corneal epithelial wound healing in rabbits. Int J Exp Pathol 2009; 90: 166173, doi: 10.1111/j.1365-2613.2008.00626.x.

27. Barbosa FL, Laicine EM, Faria-e-Sousa SJ, Haddad A. Regeneration of corneal epithelium in rabbit eyes. Acta Microscopica 2003; 12: 463-464.

28. Cotsarelis G, Cheng SZ, Dong G, Sun TT, Lavker RM. Existence of slow-cycling limbal epithelial basal cells that can be preferentially stimulated to proliferate: implications on epithelial stem cells. Cell 1989; 57: 201-209, doi: 10.1016/0092-8674(89)90958-6.

29. Lehrer MS, Sun TT, Lavker RM. Strategies of epithelial repair: modulation of stem cell and transit amplifying cell proliferation. J Cell Sci 1998; 111 (Part 19): 2867-2875.

30. Lavker RM, Tseng SC, Sun TT. Corneal epithelial stem cells at the limbus: looking at some old problems from a new angle. Exp Eye Res 2004; 78: 433-446, doi: 10.1016/ j.exer.2003.09.008.

31. Thoft RA, Friend J. The $X, Y, Z$ hypothesis of corneal epithelial maintenance. Invest Ophthalmol Vis Sci 1983; 24 1442-1443.

32. Majo $F$, Rochat $A$, Nicolas M, Jaoude GA, Barrandon $Y$ Oligopotent stem cells are distributed throughout the mammalian ocular surface. Nature 2008; 456: 250-254, doi: 10.1038/nature07406.

33. Buck RC. Measurement of centripetal migration of normal corneal epithelial cells in the mouse. Invest Ophthalmol Vis Sci 1985; 26: 1296-1299.

34. Nagasaki T, Zhao J. Centripetal movement of corneal epithelial cells in the normal adult mouse. Invest Ophthalmol Vis Sci 2003; 44: 558-566, doi: 10.1167/iovs.02-0705.

35. Barbosa FL, Goes RM, de Faria-e-Sousa SJ, Haddad A. Regeneration of the corneal epithelium after debridement of its central region: an autoradiographic study on rabbits. Curr Eye Res 2009; 34: 636-645, doi: 10.1080/02713680903007121.

36. Rogers AW. Techniques of autoradiography. 2nd edn. Amsterdam: Elsevier; 1979.

37. Salpeter MM, Budd GC, Mattimoe S. Resolution in autoradiography using semithin sections. J Histochem Cytochem 1974; 22: 217-222, doi: 10.1177/22.4.217.

38. Leblond CP. The time dimension in histology. Am J Anat 1965; 116: 1-27, doi: 10.1002/aja.1001160102.

39. Lavker RM, Dong G, Cheng SZ, Kudoh K, Cotsarelis G, Sun TT. Relative proliferative rates of limbal and corneal epithelia. Implications of corneal epithelial migration, circadian rhythm, and suprabasally located DNA-synthesizing keratinocytes. Invest Ophthalmol Vis Sci 1991; 32: 18641875.

40. Kuwabara T, Perkins DG, Cogan DG. Sliding of the epithelium in experimental corneal wounds. Invest Ophthalmol 1976; 15: 4-14. 